\title{
Pela conjugação das abordagens variacionista e difusionista
}

\author{
MARIA CECÍLIA MOLLICA \\ PAULA BARRETO DE MATTOS \\ Universidade Federal do Rio de Janeiro
}

\section{Abstract}

This study intends to show the complementarity of the variationist and the diffusionist models. The conjunction of the two models makes it possible for us to control linguistic, extralinguistic and lexical parameters, which leads to a more encompassing analysis since it allows us to take into account variable and invariable data. This is shown in our analysis of the variable process of $/ \mathrm{d} /$ assimilation in the context/-ndo/ in words such as 'falando', 'mundo', 'ando'. 


\section{OBJETO E OBJETIVO}

sse trabalho ${ }^{1}$ pretende demonstrar a viabilidade da conjugação de metodo-
logias de análise multivariacional e difusionista no estudo de fenômenos
variáveis, discutindo sua complementaridade e as vantagens dela decorren-
tes. Não intenciona levantar questões clássicas como a referente às causas
do início e implementação de uma inovação e/ou mudança sonora, consagrada na famosa controvérsia neogramática (cf. Wang, 1969 e Labov, 1981). Seu intento é o de tão somente evidenciar, empiricamente, o interesse em conjugar metodologias de análise para fenômenos de variação e/ou mudança.

A abordagem multivariacional permite conhecer a correlação de fatores intralingüisticos e extralingüisticos (cf. Labov, 1966 e 1972) apenas para os dados atingidos pela variação. Assim, todos os dados não atingidos pela variação fícam exclúdos do estudo. Uma análise difusionista leva em conta todos os itens individualmente, tornando possivel estabelecer a relação entre os itens atingidos pela variação e os itens não atingidos, bem como identificar os parâmetros que regulam o universo lexical não atingido pela variação ou mudança.

Operacionalizamos nosso objetivo através do estudo do processo de assimilação fonológica da dental sonora em. contexto /-ndo/. Esse processo encontra-se estável no português moderno conforme comprovado em Mattos e Mollica (1989). Constatamos, ali, que o fenômeno em questão não atua uniformemente no léxico da língua portuguesa, seja porque não atinge os itens potencialmente sujeitos ao afetamento, seja porque nem todas as categorias gramaticais são atingidas.

\section{ETAPAS PRELIMINARES}

Os dados utilizados para a análise foram coletados dos 64 falantes não universitários do Município do Rio de Janeito que compõem a Amostra Censo. Foram ouvidas 32 hotas de fala ( 30 minutos de cada entrevista), totalizando 4235 dados. $\mathrm{Na}$ análise multivariacional, foram levados em conta apenas os dados variáveis, isto é, 4101 dados. Fazem parte do conjunto de vocábulos invariáveis os nomes próprios, como 'Orlando', os nomes comuns (com exceção de 'mundo'), a maior parte dos adjetivos, como 'redondo' e 'profundo', e o numeral e conjunção 'segundo'. Tais itens foram estudados em separado na abordagem difusionista. Se tivéssemos escolhido trabalhar apenas com a descrição laboviana, todo esse universo lexical teria ficado fora do estudo. 
Cabe relembrar que, do ponto de vista difusionista, prevê-se que as inovações se instalem gradualmente no léxico. Sob esse prisma, admite-se que a mudança não se dê uniformemente na língua num mesmo estágio temporal e que seus condicionamentos possam ser de natureza diversa. Assume-se que a implementação de uma mudança se processa por razões de ordem lexical, ora como propulsoras ora como refreadoras (cf. Wang, 1969; Wang, 1977; Hsieh, 1972), além de motivações fonéticas, sócio-geográficas e outras, levando em conta a dimensão temporal.

No estudo realizado sobre a assimilação ndo > no, procedemos a uma classificação dos tipos de dados de contexto 'ndo' com que trabalhamos. O critério utilizado não se baseou cm cânones tradicionais, mas numa mistura entre categoria morfológica e grau de variabilidade do fenômeno. Por exemplo, os verbos receberam uma classificação tripartida: verbos no 'presente do indicativo', 'gerúndios verbais', 'gerúndios fáticos'. Chegamos à seguinte distribuição:

1) gerúndio - Eu estava procurando o carro. (Ed., casa 7, 41a, $4^{\mathrm{a}} \mathrm{s}$ )

2) verbo no presente do indicativo - Eu não pretendo mais morar aqui não. (Sa., casa $1,18 \mathrm{a}, 4^{\mathrm{a}} \mathrm{s}$ )

3) substantivo comum - Todo mundo tem que trabalhar. (Ja., casa 3, 56a, 4 $4^{\mathrm{a}} \mathrm{s}$ )

4) substantivo próprio-Olha, o Laurindo deixou isso aqui. (Ag., casa 33, 60a, 5's)

5) gerúndio fático (formas gerundiais esvaziadas de sentido que revelam valor fático) - E olha que eu conheço, tá entendendo? (Geo., casa 31, 58a, 8 ${ }^{\mathrm{a}} \mathrm{s}$ )

6) outros - Ela adora quando eu faço macartonada. (Lou., casa 16, 56a, $4^{\mathrm{a}} \mathrm{s}$ )

A Tab. 1 apresenta o percentual de preservação da dental de acordo com a classificação proposta para os itens lexicais constitutivos do léxico envolvido.

\section{TABELA 1}

Percentual de preservação de /d/ em 'ndo' de acordo com o tipo de item Itens variáveis

\begin{tabular}{l|l|ll}
\hline Tipo de item gramatical & \multicolumn{1}{|c|}{ Quantidade } & Percentual \\
\hline gerúndio & $1606 / 2602$ & $62 \%$ & \\
verbo no presente & $56 / 62$ & $90 \%$ & \\
substantivo comum & $292 / 314$ & $93 \%$ & \\
gerúndio fático & $32 / 70$ & $46 \%$ & \\
outros & $858 / 1053$ & $81 \%$ & \\
\hline
\end{tabular}

Segundo essa distribuição, a maior incidência de ausência do segmento /d/ em contexto 'ndo' encontra-se entre os gerúndios, acentuando-se mais entre os gerúndios fáticos. Já os verbos que, no presente do indicativo, contêm 'ndo' no radical apresentam uma tendência à maior preservação de $/ \mathrm{d} /$, sendo a taxa de preservação destes apenas menor que a taxa dos substantivos comuns. 


\section{ANÁLISE VARIACIONISTA}

Como ficou constatado que as categorias 'substantivo próprio' e 'adjetivo' são invariáveis (cf. Mattos e Mollica, 1989), estas foram retiradas da análise variacionista quantitativa. $\mathrm{Na}$ análise variacionista, a variável que se mostrou mais relevante foi Extensão do Vocábulo, que classificava cada item de acordo com seu número de sílabas, assim:

a) dissílabo - Essas coisas estão sendo providenciado tudo. (Re., cada 15, 22a, $4^{2}$ s)

b) trissílabo - Teu pai está fazendo o quê? (Jo., casa 10, 27a, $4^{\circ} \mathrm{s}$ )

c) polissílabo - E a gente acabou namorando e noivou e casamos. (Gl., casa 11, $\left.48 \mathrm{a}, 6^{9} \mathrm{~s}\right)$.

Na Tab. 2 encontramos os resultados, percentuais e probabilísticos, para a variável Extensão do Vocábulo, fornecidos pelo programa VARBRUL 2S. (cf. Naro \& Votre, 1980).

TABELA 2

Variável 'Extensão do vocábulo': Preservação de/d/ em 'ndo':

\begin{tabular}{c|c|c|c}
\hline $\begin{array}{c}\text { Extensão do } \\
\text { vocábulo }\end{array}$ & Aplicação & Percentagem & Probabilidade \\
\hline dissílabo & $1311 / 1619$ & $81 \%$ & .53 \\
+ de 2 sílaba & $1533 / 2482$ & $63 \%$ & .46 \\
\hline TOTAL & $2824 / 4101$ & $69 \%$ & \\
\hline
\end{tabular}

Os resultados quanto à variável Extensão do Vocábulo nos revelam que quanto maior é o item, maior a chance de se operar a assimilação. Isso pode ser explicado se levamos em consideração fatores de processamento que atuam no nivel da unidade da palavra (cf. Mollica, 1989): os segmentos tendem à não realização, quando as cadeias vocabulares são grandes. Note-se que esse não é um fator de natureza estritamente fonética mas, antes, de caráter psicolingüistico.

A variável Segmento Fonológico Seguinte, de caráter propriamente fonético-fonológico, que controla o que vem imediatamente depois do 'ndo' (silêncio, vogal, segmento nasal, consoante 'd', hesitação ou outra consoante), não apresentou o resultado esperado (isto é, 'silêncio' favorecendo a manutenção de /d/ e os demais fatores favorecendo sua assimilação). Só encontramos relevância para essa variável estrutural quando analisamos as formas de gerúndio em separado. Isso demonstra que tal variável não atua em todo o léxico e que só um exame que diferenciasse os tipos de itens lexicais pôde nos revelar sua influência no fenômeno em questão. Observemse os resultados na Tab. 3: 


\section{TABELA 3}

Formas gerundiais - Preservação de /d/ em 'ndo' Variável: Segmento Fonológico Seguinte

\begin{tabular}{c|c|c|c}
\hline Segmento seguinte & Aplicação & Porcentagem & Probabilidade \\
\hline silêncio & $273 / 412$ & $66 \%$ & .53 \\
não-silêncio & $1327 / 2184$ & $61 \%$ & .46 \\
\hline TOTAL & $1600 / 2596$ & $62 \%$ & \\
\hline
\end{tabular}

Foi feita aqui uma oposição entre silêncio (pausa) e não-silêncio (qualquer outro ambiente fonológico que não seja pausa). $O$ segmento / $d /$ tende a ser mais preservado quando seguido de silêncio, pois neste ambiente não há qualquer fonema próximo que favoreça a assimilação. Pode-se afirmar que o resultado encontrado, embora estatisticamente pouco relevante, contraria os postulados neo-gramáticos, uma vez que ofator fonético-fonológico que controla o contexto favorecedor da assimilação só se aplica a uma categoria gramatical.

\section{ANÁLISE DIFUSIONISTA}

Por que todos os itens não são regulados numa distribuição eqüitativa por tal condicionamento? Além de pouco salientes, as estatisticas suscitam estranheza. É oportuno questionar, então. Quais são os princípios que regulam o afetamento ou não afetamento dos itens com condicionamentos idênticos?

Para responder a essa questão, elaboramos um glossário que nos permitiu controlar o afetamento e o não afetamento da referida assimilação no universo lexical envolvido. Correlacionamos, então, parâmetros utilizados em estudos de linha difusionista com o indice de afetamento da variação. Baseando-nos em Phillips (1984), utilizamo-nos da variável Freqüência e relacionamos a frequiência de todos os itens à taxa de preservação de $/ d /$. O resultado pode ser visto nas Tab. 4 e 5:

\section{TABELA 4}

Relação da preservação de /d/ em /-ndo/ com a freqüência dos itens

(100\% de preservação)

\begin{tabular}{l|c|c|c|c|c|c|c}
\hline Ocorrências & $1-3$ & $4-6$ & $7-10$ & $11-20$ & $21-40$ & $41-59$ & $60+$ \\
Casos & 197 & 8 & 2 & 4 & - & - & - \\
\hline
\end{tabular}

\section{TABELA 5}

Relação da assimilação de /d/ em /-ndo/ com a freqüência dos itens ( 0 a $99 \%$ de preservação)

\begin{tabular}{l|c|c|c|c|c|c|c}
\hline Ocorrências & $1-3$ & $4-6$ & $7-10$ & $11-20$ & $21-40$ & $41-59$ & $60+$ \\
Casos & 140 & 46 & 21 & 25 & 15 & 10 & 6 \\
\hline
\end{tabular}


Vale mencionar que a distribuição das faixas de ocorrência foi arbitrária. A Tab. 4 nos mostra que quase todos os itens invariáveis, com preservação total da dental, constituem itens de baixa ocorrência (197 itens na faixa de 1 a 3 ocorrências). Nota-se também que esta Tabela não contém itens de freqüência alta. Já a Tab. 5, referente aos itens que sofreram assimilação, apresenta uma distribuição mais equilibrada entre as faixas de freqüência. Entretanto, aqui também a faixa de $\mathbf{1}$ a 3 ocorrências apresenta um grande númeto de itens lexicais.

Correlacionamos também o percentual de variação ndo/no com a categoria gramatical do item, conforme exposto na Tab. 6

\section{TABELA 6}

Relação entre a categoria gramatical do item e a taxa de variação.

Preservação do segmento /d/

\begin{tabular}{c|c|c|c|c|c|c}
\hline $\begin{array}{c}\text { Nome } \\
\text { próprio }\end{array}$ & Adjetivo & Numeral & $\begin{array}{c}\text { Verbo } \\
\text { pres. }\end{array}$ & $\begin{array}{c}\text { Nome } \\
\text { comum }\end{array}$ & Conector & Gerúndio \\
\hline $12 / 12$ & $28 / 28$ & $61 / 62$ & $104 / 111$ & $336 / 362$ & $856 / 1049$ & $1639 / 2673$ \\
$98 \%$ & $94 \%$ & $93 \%$ & $82 \%$ & $61 \%$ \\
\hline
\end{tabular}

Confirma-se que as formas gerundiais são as que apresentam maior variabilidade. Os verbos em geral costumam ser o conjunto de itens a sofrer processo de inovação fonológica. O contraste entre a taxa de variação dos gerúndios e dos verbos no presente do indicativo poderia ser explicado pelo fato de 'ndo' não fazer parte do radical do verbo nas formas gerundiais, mas ser a ele afixado. Note-se que /d/, sendo parte da raiz, como em nomes, conjunções ou verbos no presente, tende a resistir mais fortemente à queda, pois se acha na unidade base (raiz) do vocábulo. Ao recair na desinência 'ndo', $/ \mathrm{d} /$ incide sobre as unidades afixais da palavra.

A preservação total do segmento /d/ entre os nomes próprios coincide com a constatação de Phillips (1984) e de Oliveira (1991) de que esta categoria constitui barreira lexical para entrada da variação na língua. $O$ fato de as categorias adjetivo, numeral e conector (as conjunções 'quando' e 'segundo') também apresentarem um altíssimo índice de preservação reforça igualmente a hipótese de que há classes gramaticais mais resistentes à inovação do que outras. Por outro lado, a categoria nome comum não foi atingida pela variação de forma significativa, o que se explica pela própria natureza do fenômeno, que sofre restrições de ordem fonológica, haja vista o fato de só encontrarmos sete nomes comuns com ambiente 'ndo': 'bando', 'comando', 'fundo', 'mundo', 'memorando', 'segundo' e 'vagabundo'. Desses, o item lexical 'mundo' é responsável pela grande maioria das ocorrências de nomes comuns (313 vezes) $\mathrm{e}$, mesmo sendo tão freqüente, não é atingido consideravelmente, dando-se o afetamento, na grande maioria das vezes, na expressão 'todo mundo'. Vale mencionar que as tendências entrevistas na Tab. 6 são corroboradas nos estudos de aférese e prótese, de Gonçalves (neste volume), e da preservação da vibrante pós-vocálica, de Lima (1990). 


\section{CONJUGAÇÃO DAS ANÁLISES}

É possivel ainda estabelecer uma relação entre a variável estrutural, controlada via análise multivariacional, com o parâmetro freqüência lexical.

Correlacionamos o número de ocortências do item lexical no corpus (fator lexical) com sua extensão (fator estrutural), a fim de verificar o peso de variáveis de natureza diferente para cada categoria gramatical. Tal cortelação foi feita separando-se os itens lexicais variáveis dos invariáveis. Nas Tab. de 7 a 11 , apresentam-se os números encontrados a partir do controle dessas variáveis para cada categoria gramatical em separado. Como as categorias numeral e concctor possuem $1 \mathrm{e} 2$ itens, respectivamente, não há quadros para elas. Para efeito de leitura, vale ressaltar que a parte esquerda dos quadros refere-se aos itens lexicais não atingidos pela variação, e a parte direita, aos itens atingidos.

\section{TABELA 7}

Gerúndio - Correlação entre frequiência e extensão

\begin{tabular}{c|c|c|c|c|c|c|c|c}
\hline & \multicolumn{2}{|c|}{ Itens não atingidos } & \multicolumn{4}{c}{ Itens atingidos } \\
\cline { 2 - 9 } $\begin{array}{c}\text { Freqüên- } \\
\text { cia }\end{array}$ & $\begin{array}{c}\text { Total de } \\
\text { itens não } \\
\text { atingidos }\end{array}$ & dissílabos & $\begin{array}{c}\text { trissila- } \\
\text { bos }\end{array}$ & $\begin{array}{c}\text { polissila- } \\
\text { bos }\end{array}$ & $\begin{array}{c}\text { Total de } \\
\text { itens atin- } \\
\text { gidos }\end{array}$ & dissilabos & $\begin{array}{c}\text { trissíla- } \\
\text { bos }\end{array}$ & $\begin{array}{c}\text { polissila- } \\
\text { bos }\end{array}$ \\
\hline $\begin{array}{c}\text { Baixa } \\
\text { 1 a 9 }\end{array}$ & 195 & 1 & 66 & 128 & 192 & 1 & 76 & 115 \\
\hline $\begin{array}{c}\text { Média } \\
10 \text { a 50 }\end{array}$ & - & - & - & - & 53 & 4 & 40 & 9 \\
\hline $\begin{array}{c}\text { Alta } \\
+50\end{array}$ & - & - & - & - & 17 & 2 & 4 & 1 \\
\hline Total & 195 & 1 & 66 & 128 & 262 & 7 & 120 & 125 \\
\hline
\end{tabular}

Segundo a Tab. 7, observa-se que a maioria dos itens lexicais gerundiais do corpus é atingida pela variação: das $\mathbf{4 5 7}$ formas gerundiais encontradas, 262 são afetadas.

A maior parte dos itens não atingidos é composta de polissílabos, o que revela que a variável Extensão do Vocábulo não está exercendo influência. Para os getúndios não atingidos, o fator preponderante é, portanto, a freqüência do item. No que tange aos itens lexicais atingidos pela variação, nota-se que o fator atuante deixa de ser 'frequiência do item', passando para 'Extensão do vocábulo': a maioria dos itens atingidos possui mais de duas sílabas.

Observe-se agora a Tab. 8, que estabelece a mesma relação para os substantivos comuns. 


\section{TABELA 8}

Substantivo comum - Correlação entre freqüência e extensão

\begin{tabular}{c|c|c|c|c|c|c|c|c}
\hline \multicolumn{4}{c|}{ Itens não atingidos } & \multicolumn{4}{c}{ Itens atingidos } \\
\hline $\begin{array}{c}\text { Freqüên- } \\
\text { cia }\end{array}$ & $\begin{array}{c}\text { Total de } \\
\text { itens não } \\
\text { atingidos }\end{array}$ & dissílabos & $\begin{array}{c}\text { trissíla- } \\
\text { bos }\end{array}$ & $\begin{array}{c}\text { polissíla- } \\
\text { bos }\end{array}$ & $\begin{array}{c}\text { Total de } \\
\text { itens atin- } \\
\text { gidos }\end{array}$ & $\begin{array}{c}\text { dissíabos } \\
\text { trissíla- } \\
\text { bos }\end{array}$ & $\begin{array}{c}\text { poliissila- } \\
\text { bos }\end{array}$ \\
\hline $\begin{array}{c}\text { Baixa } \\
\text { 1 a 9 }\end{array}$ & 4 & 1 & 2 & 1 & 1 & - & - & 1 \\
\hline $\begin{array}{c}\text { Média } \\
\text { 10 a 50 }\end{array}$ & - & - & - & - & 1 & 1 & - & - \\
\hline $\begin{array}{c}\text { Alta } \\
+50\end{array}$ & - & - & - & - & 1 & 1 & - & - \\
\hline Total & 4 & 1 & 2 & 1 & 3 & 2 & - & 1 \\
\hline
\end{tabular}

A Tab. 8 nos revela que os substantivos comuns não atingidos pela variação são os menos freqüentes, que ocorreram uma ou duas vezes no corpus. Para os itens atingidos, a variável Freqüência (do item) também prevaleceu, pois os substantivos comuns afetados pela variação são justamente os mais freqüentes (distribuição eqüitativa entre freqüência média e frequiência alta), com exceção de um item. Em contrapartida, esse único item afetado é polissilábico, donde se pode constatar que há sempre um fator responsável, quer estrutural, quer lexical, pelo favorecimento da inovação.

Por não havermos encontrado substantivos próprios atingidos pela variação, o Tab. 9 assim se resume:

TABELA 9

Substantivo próprio - Cotrelação entre freqüência e extensão

\begin{tabular}{c|c|c|c|c}
\hline \multicolumn{5}{c}{ Itens não atingidos } \\
\hline Freqüência & $\begin{array}{c}\text { Total de itens não } \\
\text { atingidos }\end{array}$ & dissilabos & trissilabos & polissilabos \\
\hline Baixa 1 a 9 & 8 & 2 & 6 & - \\
\hline $\begin{array}{c}\text { Média } \\
10 \text { a 50 }\end{array}$ & - & - & - & - \\
\hline $\begin{array}{c}\text { Alta } \\
+50\end{array}$ & - & - & - & - \\
\hline Total: & 8 & 2 & 6 & - \\
\hline
\end{tabular}

A Tab. 9 nos mostra que os substantivos próprios têm baixa ocorrência, o que já constitui razão para ser uma categoria pouco afetada. Temos aqui a conjugação de dois fatores lexicais atuando: 'categoria gramatical' mais 'freqüência'. 
Assim como os substantivos próprios, os adjetivos também não foram afetados pela variação. Vejamos então a Tab. 10, que se refere a esta categoria:

TABELA 10

Adjetivos - Correlação entre freqüência e extensão

\begin{tabular}{c|c|c|c|c}
\hline \multicolumn{5}{c|}{ Itens não atingidos } \\
\hline Freqüência & $\begin{array}{c}\text { Total de itens não } \\
\text { atingidos }\end{array}$ & dissilabos & trissílabos & polissílabos \\
\hline $\begin{array}{c}\text { Baixa } \\
\text { a 9 }\end{array}$ & 4 & - & 3 & 1 \\
\hline $\begin{array}{c}\text { Média } \\
10 \text { a 50 }\end{array}$ & 1 & 1 & - & - \\
\hline $\begin{array}{c}\text { Alta } \\
+50\end{array}$ & - & - & - & - \\
\hline TOTAL: & 5 & 1 & 3 & 1 \\
\hline
\end{tabular}

Além de poucos dados, não há aqui distribuição equilibrada do ponto de vista da extensão do item. Mesmo assim, vale ressaltar que a maioria dos adjetivos encontrados no corpus apresenta baixa freqüiência, com exceção de um item lexical (de frequiência média). Arriscariamos dizer que a freqüência e a categoria gramatical é que parecem influir na forma de afetamento dos adjetivos.

Observemos a Tab. 11, referente aos verbos no presente do indicativo:

TABELA 11

Verbo no presente - Correlação entre frequiência e extensão

\begin{tabular}{c|c|c|c|c|c|c|c|c}
\hline \multirow{2}{*}{$\begin{array}{c}\text { Frequêen- } \\
\text { cia }\end{array}$} & \multicolumn{3}{|c|}{ Itens não atingidos } & \multicolumn{4}{c}{ Itens atingidos } \\
$\begin{array}{c}\text { itens nâo } \\
\text { atingidos }\end{array}$ & dissílabos & $\begin{array}{c}\text { trissila- } \\
\text { bos }\end{array}$ & $\begin{array}{c}\text { polissila- } \\
\text { bos }\end{array}$ & $\begin{array}{c}\text { Total de } \\
\text { itens atin- } \\
\text { gidos }\end{array}$ & $\begin{array}{c}\text { dissílabos } \\
\text { trissíla- } \\
\text { bos }\end{array}$ & $\begin{array}{c}\text { polissila- } \\
\text { bos }\end{array}$ \\
\hline $\begin{array}{c}\text { Baixa } \\
\text { 1 a 9 }\end{array}$ & 3 & - & 1 & 2 & 3 & 1 & 2 & - \\
\hline $\begin{array}{c}\text { Média } \\
10 \text { a 50 }\end{array}$ & 2 & 2 & - & - & 2 & - & 2 & - \\
\hline $\begin{array}{c}\text { Alta } \\
+50\end{array}$ & - & - & - & - & - & - & - & - \\
\hline Total & 5 & 2 & 1 & 2 & 5 & 1 & 4 & - \\
\hline
\end{tabular}

Três dos verbos não atingidos têm mais de três sílabas, mas apresentam baixa ocorrência, o que nos leva a supor que a variável atuante aqui é Freqüência do Item, desfavorecendo o afetamento do processo de assimilação. Além disso, a categoria dos verbos apresenta dois itens dissilábicos não afetados com índice médio de freqüência. Quanto aos verbos atingidos pela variação, parece haver um balanceamento entre 'freqüência' e 'extensão': duas formas verbais são de freqüềncia média e duas outras são pouco freqüentes, mas as quatro são de extensão média (três sílabas). 
Ao comparar os resultados do Tab. 11 com os resultados das Tab. anteriores, pode-se dizer que os parâmetros analisados são menos salientes aqui. Esta questão só pode ser entendida pelo fato de 'nd' ser inerente ao radical e não ser uma desinência flexional.

\section{CONSIDERAÇÕES TEÓRICO-METODOLÓGICAS}

Após analisar essa série de quadros que correlacionam variáveis de natureza estrutural e lexical, constatamos que há resultados que confirmam as propostas feitas na literatura sobre difusão lexical, na medida em que atestam a pertinência de condicionamentos lexicais como controladores de inovações. A título de ilustração, examine-se a taxa de variação correspondente a cada categoria gramatical (cf. Tab. 6). Há, por outro lado, outros quadros que apresentam tendências menos favoráveis à hipótese, atestando maior importância para fatores estruturais. Concluímos, portanto, que estamos lidando com uma situação de ponderação de fatores: quando um fator atua, o outro pode deixar de atuar. Tal constatação reforça a tese de que os dois tratamentos analíticos (variacionista e difusionista) se complementam, conforme discutido em Reighard (1977 e inédito). A força na complementaridade das duas análises, entretanto, é tanto mais eficiente quanto maior for a certeza a respeito dos condicionamentos estruturais e lexicais apontados pelas análises multivariacional e difusionista, respectivamente.

Gostaríamos de destacar alguns pontos que se referem estritamente ao estudo em questão. O processo de assimilação 'ndo'> 'no' tem sua estabilidade controlada por diferentes fatores: sociais, estruturais, lexicais. Se, por um lado, o efeito da dimensão social não foi aqui discutido (cf. Mattos e Mollica, 1989), por outro lado, foi possivel apresentar o efeito dos parâmetros estruturais e lexicais considerados como pertinentes. No entanto, esses possuem peculiaridades que devem ser salientadas. Merecem especial destaque: a) o condicionamento propriamente fonético-fonológico, Segmento Fonológico Seguinte, mostra-se relevante somente entre as formas gerundiais; b) Extensão do Vocábulo, ainda que entendido como estrutural (posto que interpretado numa perspectiva psicolingüística), pode, em última análise, receber o rótulo de condicionamento lexical, pois diz respeito a características (no caso 'dimensão') dos itens lexicais; c) os fatores categorizados como lexicais apresentam interfaces estruturais: categorias morfológicas têm a ver, obviamente, com o nível morfo-sintático da lingua e tendem, em geral, a apresentar comportamentos freqüenciais típicos.

De acordo com a classificação de Shen (comunicação pessoal), esse é um caso em que se associa variação fonológica a difusão fonológica e morfo-sintática. Resta considerar, por último, que a análise realizada ainda pode ser entendida como limitada, na medida em que só trabalhamos com dados de um mesmo estado de tempo, e isto não é recomendável devido à própria premissa de gradualidade temporal do modelo difusionista. Ademais, os estudos mais recentes, tais como de Shen (1990) e o de Wang (1990), dimensionam também a difusão sob uma perspectiva populacional, de modo a permitir-se observar a implementação de uma inovação e/ou mudança não só de "palavra para palavra", como também de "individuo para individuo". 


\section{NOTA}

${ }^{1}$ A versão mais completa desse estudo encontra-se no Relatótio Final FINEP do projeto "Mecanismos Funcionais do Uso da Língua" convênio UFRJ/FINEP. Uma outra versão foi apresentada na mesa sobre Difusão Lexical, no GT de Sociolingüistica do V Encontro Nacional da ANPOLL, em Recife, cujo resumo encontra-se nos Anais do referido congresso.

\section{REFERÊNCIAS BIBLIOGRÁFICAS}

GONÇALVES, Carlos A. Victório. Aférese e prótese: verso e reverso fonológico. In: ENCONTRO NACIONAL DA ANPOLL, 5, 1990. Comunicação apresentada... Recife: UFPE, 1990. 15 p. (Mimeogr.)

HSIEH, H-I. Lexical diffusion: evidence from child language acquisition In: WANG W.S-Y.(ed.). The lexicon in phonological change. The Hague: Mouton, 1977. p. 133-47.

LABOV, William. The Social Stratification of English in New York city. Washington, Center for applied Linguistics, 1966.

LABOV, Willian . Sociolinguistics patterns. Philadelphia, University of Pennsylvania Press, 1972.

LABOV, William. Resolving the Neogrammarian Controversy. In: Language. v. 57, n.2, p.257-308, junho, 1981.

LIMA, Joana D'arc de Matos. O - $\mathrm{r}$ en dois tempos: ou no principio era o verbo. In: ENCONTRO NACIONALC DA ANÁPOLL, 5, 1990, Recife. Comunicação apresentada... Recife: UFPE, 1990. 15 p. (mimeogr.)

MATTOS, Paula Barreto e MOLLICA, Maria Cecilia M. Abordagem variacionista e difusionista em processo fonológico. In: ENCONTRO NACIONAL DA ANPOLL, 5, 1990, Recife. Comunicação apresentada... Recife: UFPE, 1990. $15 \mathrm{p}$ (Mimeogr.)

MOLLICA , Maria Cecilia M. Influência de fatores de processamento na variação em português". In: TARALLO, F. (org.) Fotografias sociolingüísticas; Campinas Editora Pontes, 1989. p.283-299

NARO, Anthony J., VOTRE, Sebastião J. Swava: Sistema SWAMINC/VARBRUL: manual do usuário. Rio de Janeiro: UFRJ, 1980. 56 p. (Mimeogr.)

OLIVEIRA, Marco A. de. The neogrammarian controversy revisited. International journal of the sociology of language, Berlin, v.89, p. 93-105, 1991.

BORTONI \& MATTOS (ed.) - International Journal of the sociology of language. p. 93 a $105,1991$. 
PHILLIPS, B. S. Word Frequency and the Actuation of Sound Change. Language, v. 60 n. 2 , p. $320-42,1984$.

REIGHARD, John. The evolution of variable rules: a case of lexical constraints. In: HAGIUNA, M.P. (ed.) Studies in romance linguistics. Rowle: Newbury House. 1977, p. 96-169.

REIGHARD, John. The trasnsition problem: lexical diffusion vs variable rules. Inédito

SHEN, Zhongwei. Lexical diffusion: a populational perspective and a numerical model. Journal of Chinese Linguistics, v.18, n.1, p.159-200, 1990.

WANG, W. S-Y. Competing Changes as a cause of residue. Language, v. 45 n.1, p. 9-25, março, 1969.

WANG, W. S-Y. Theoretical issues in studying chinese dialects. JCLT, v.25, n.1, p. 1-34, fevereiro, 1990.

WANG, W. S-Y.,CHENG, C-C. Implementation of phonological change: The Suangfeng- Chinese case. In: WANG, W. S-Y. (ed.) The lexicon in phonological change. The Hague: Mouton, 1977. p. 148-158. 